\title{
Iodine nutrition status among schoolchildren after salt iodisation
}

\author{
R Jayatissa', MM Gunathilaka ${ }^{2}$ and DN Fernando ${ }^{3}$ \\ (Index words: Goitre rate, household salt iodine level, urinary iodine)
}

\begin{abstract}
Earlier studies done in Sri Lanka have indicated the importance of iodine deficiency as a public health problem. The universal salt iodisation programme has been implemented since 1995. The goals of salt iodisation are reduction of the goitre rate to $<5 \%$ in school-aged children, to maintain the median urinary iodine level in the population between $100-200 \mu \mathrm{g} / \mathrm{L}$ and $>90 \%$ of households using iodised salt.
\end{abstract}

Objective To estimate the goitre prevalence, the urinary iodine level, and measure the household iodised salt consumption pattern by Province.

Method A school-based study of 6574 randomly selected children in the age group 8-10 years, from 263 schools was assessed for goitre by palpation. The concentration of urinary iodine levels was measured in 2630 of these children. Estimation of iodine in the 6181 samples of salt used in households of the schoolchildren was also assessed by test kits.

Results The prevalence of goitre in the Provinces varied from $16.3 \%$ to $26.2 \%$. The median urinary iodine levels were above the cut-off point of $100 \mu \mathrm{g} / \mathrm{L}$ in all Provinces except in Uva. The highest median urinary iodine level was reported in North Central Province $(231.3 \mu \mathrm{g} / \mathrm{L})$. Overall, $35.4 \%$ of the children had urine iodine levels in the 'ideal' range (100-199.9 $\mu \mathrm{g} / \mathrm{L}) ; 30.6 \%$ with lower values $(<100 \mu \mathrm{g} / \mathrm{L})$ indicated iodine deficiency and $16.3 \%$ with higher values $(<300 \mu \mathrm{g} / \mathrm{L})$ indicated excessive iodine intake. Only $49.5 \%$ of households had used adequately iodised salt.

Conclusions This study showed that iodine deficiency still exists in Uva Province, and that more than adequate iodine levels were found in the North Central Province. The level of permitted salt iodine at household level needs to be revised.

\section{Introduction}

The gravity of the problem of iodine deficiency is evident from the estimation that 172 million people in the south-east Asia region have goitre, and a further 599 million are at risk [1].

The first of the goitre studies made in Sri Lanka (then Ceylon) was in 1947/9. Results of that study suggested the existence of an endemic area for iodine deficiency (goitre belt) in Sri Lanka. It was confined to the south- west region of the island extending over the whole of the Western, Sabaragamuwa, Central and Southern Provinces and part of the Uva Province, which constitute the wet zone of the country, with a very high annual rainfall of $250-500 \mathrm{~cm}$. Over $70 \%$ of the population of the island resides in this zone [2]. The high annual rainfall in this area was believed to leach the soil of iodine resulting in iodine deficiency [3].

In 1950, a study of three Provinces of Sri Lanka showed that the incidence of enlarged thyroid in schoolgirls was high, the iodine content of drinking water was low and the usual diet was poor in iodine. Therefore a lack of iodine in food and water was considered to be of primary aetiological importance [4]. Mahadeva in the 1960s reported that endemic goitre was not associated with cretinism or deaf mutism to any significant extent [2].

In a 1963 study, the highest incidence of goitre was found in the region between the Kelani Ganga and the Kalu Ganga rivers in the south-western part of the island. Almost no goitres were found in the Northern, Eastern, and North Western Provinces [5]. A rapid clinical survey in 1966 investigated iodine metabolism in endemic goitre in order to establish its aetiology and it found that even in endemic regions, iodine deficiency was mild, but indicative of environment iodine deficiency [5].

1986/7 national prevalence survey in 17 of 24 districts included 59/158 schoolchildren, aged between 5 and 19 years from 87 schools. The overall goitre prevalence rate was $18.8 \%$ and varied by district, from $6.5 \%$ in Matale to $30.2 \%$ in Kalutara [6]. This study indicated that all 17 districts should be considered endemic, with about $86 \%$ of the country's population at risk of goitre. Goitre prevalence was also high $(63 \%)$ among 1641 pregnant women examined during a survey conducted in 1987-89 by the Medical Research Institute (MRI) in Kalutara district [unpublished].

In view of these findings, the Government of Sri Lanka introduced the universal salt iodisation (USI) programme, and legislation was adopted in 1995 requiring that salt sold for human consumption should have an iodine content of $50 \mathrm{ppm}$ at the factory and $25 \mathrm{ppm}$ at the consumer level.

The success of USI for the control of the iodine deficiency disorders (IDD) requires monitoring of its effect at population level. The principal indicator of effect is the

${ }^{1}$ Community Physician and Nutritionist, ${ }^{2}$ Chemical Pathologist, Medical Research Institute, Colombo, and ${ }^{3}$ Professor of Community Medicine, Faculty of Medicine, University of Colombo, Sri Lanka.

Correspondence:RJ, Tel: + 0112695 999, e-mail:< amal@eureka.lk >. (Competing interests: none declared). Received 15 January 2005 and revised version accepted 28 September 2005. 
median urinary iodine concentration (UI) because it is highly sensitive to recent changes in iodine intake. It should be maintained between 100-200 $\mu \mathrm{g} / \mathrm{L}$ in the population. A second indicator is thyroid size, as shown by the goitre rate (GR), which is a poor indicator of effect because it reflects a population's history of iodine nutrition but not its present iodine status. The reduction of the GR to $<5 \%$ in school-aged children probably indicates the disappearance of IDD as a significant public health problem. A third indicator is the proportion of households consuming effectively iodised salt which should be $>90 \%$ [7].

The aims of this study were to estimate the prevalence of goitre, the urinary iodine level among primary schoolchildren, and to assess the level of iodine in the salt in households in each Province.

\section{Methods}

A cross-sectional school-based national study was carried out among children. The calculated sample size for each Province was 300 after considering the estimated prevalence of goitre as $30 \%$ with a $95 \%$ of confidence interval and 5\% error. A total of 2700 children were needed to determine UI to assess the current iodine status. The study population was identified as schoolchildren aged 8-10 years.

A representative sample was obtained to estimate iodine status at Provincial level. Thirty schools were selected from each Province using a probability proportionate sampling technique from the school census 2000 data, which identified a total of 270 schools from all Provinces. It is expected that children in Grade 4 would be aged 8-10 years. The number of Grade 4 classes in each school varied, and one Grade 4 class from each selected school was randomly selected. All children in the selected class were examined for goitre and all of them were asked to bring a sample of salt from their households to test the level of iodine. From the selected class, 10 children were randomly selected using the attendance register to measure urine iodine level.

Ethical approval was taken from the ethical committee of MRI, and permission was obtained from the relevant authorities. Written consent was obtained from the parent or guardian of children who were selected for the study. All fieldwork was completed during the period September 2000-January 2001.

\section{Clinical examination for goitre}

Five Public Health Inspectors were trained to assess the goitre by palpation. Grading of goitre was done according to the system classified by WHO/UNICEF/ ICCIDD 1992 [7]. About 50\% of children were re-examined for goitre by a medical officer, trained for the study.

\section{Biochemical estimations of urinary iodine}

In each school, 10 children were randomly selected to measure urine iodine level. Urine samples were to be collected from 2700 children, of whom 2630 children attending 263 schools in all nine Provinces provided samples, i.e. $97.3 \%$ of the expected sample. Children from seven schools from the Northern and Eastern Provinces could not be included due to the prevailing ground situation. The urine samples were stored at $-20^{\circ} \mathrm{C}$, transported to the laboratory of the MRI in cold packs, and stored at $-20^{\circ} \mathrm{C}$. The iodine concentration of urine was assessed by a modified microplate method [8], within the shortest possible time, on reaching the MRI. Internal quality control was performed by using samples with known values in three different concentrations (low, medium and high). External quality controls were performed using five unknown samples in different concentrations, made available by the University Hospital for Children, Brussels, Belgium. Samples of urine with known iodine levels were sent to selected study areas, and retested to assess changes in iodine values during transportation. There were no significant changes observed in iodine levels during transport.

\section{Estimation of iodine content of salt at household level}

Iodine content of salt consumed by a sample of children was considered as a proxy measure to assess the household salt iodine level. All children in selected classes were requested to bring a sample of salt from home to school in a polythene pack. The level of iodine in the salt samples was determined using rapid field test kits.

\section{Statistical methods}

Data was expressed as median with the range. Weighted percentages were calculated. Chi-square test was used to test the possible difference between two groups. A statistical result was considered significant if $\mathrm{P}<0.05$.

\section{Results}

A total of 7076 children from nine Provinces were identified for inclusion in the study. Of them, $51.0 \%$ were boys. The mean age of children was $9.8(\mathrm{SD}=0.94)$ years.

\section{Prevalence of goitre}

Due to the prevailing ground situation in the north and east of Sri Lanka, it was not possible to conduct clinical examination for goitre of children selected from the Northern and Eastern Provinces. Therefore, only 6574 children ( $92.9 \%$ of total children selected for the study) were examined for goitre.

The overall prevalence of the total goitre rate (TGR) was $20.9 \%$ (Table 1). The TGR varied between Provinces with the highest prevalence being in the North Central Province $(26.2 \%)$ and the lowest in the Western Province $(16.3 \%)$. The TGR was higher among girls $(24.5 \%)$ than among boys (17.5\%). The sex difference in the prevalence of Grade 1 goitre was most marked in the Central Province, i.e. $19.6 \%$ and $31.6 \%$ among boys and girls respectively. The highest prevalence of Grade 2 goitre was seen among girls in the Uva Province (3.3\%). 
Table 1. Goitre prevalence in children of 8-10 years by gender and Provinces

\begin{tabular}{|c|c|c|c|c|c|c|c|c|c|}
\hline \multirow[t]{2}{*}{ Province } & \multicolumn{3}{|c|}{ Boys } & \multicolumn{3}{|c|}{ Girls } & \multicolumn{3}{|c|}{ Total } \\
\hline & Gr. 1 & Gr. 2 & $T G R$ & Gr. 1 & Gr. 2 & $T G R$ & Gr. 1 & Gr. 2 & $T G R^{*}$ \\
\hline Western $(n=1006)$ & 15.3 & 1.0 & 16.2 & 15.5 & 0.8 & 16.4 & 15.4 & 0.9 & 16.3 \\
\hline Southern $(n=856)$ & 13.2 & 0.9 & 14.0 & 18.6 & 2.0 & 20.6 & 15.7 & 1.4 & 17.1 \\
\hline Uva $(\mathrm{n}=926)$ & 21.6 & 0.2 & 21.8 & 27.0 & 3.3 & 30.3 & 24.3 & 1.7 & 26.0 \\
\hline North Central $(\mathrm{n}=878)$ & 22.5 & 0.4 & 23.0 & 28.4 & 1.2 & 29.5 & 25.4 & 0.8 & 26.2 \\
\hline Central $(n=873)$ & 19.4 & 0.2 & 19.6 & 31.3 & 0.3 & 31.6 & 24.1 & 0.2 & 24.3 \\
\hline Sabaragamuwa $(\mathrm{n}=1075)$ & 14.6 & 0.2 & 14.8 & 24.0 & 0.6 & 24.6 & 19.1 & 0.4 & 19.4 \\
\hline North Western $(\mathrm{n}=960)$ & 13.0 & 0.2 & 13.2 & 20.6 & 0.4 & 21.0 & 16.9 & 0.3 & 17.2 \\
\hline Overall $(n=6733)$ & 17.1 & 0.4 & 17.5 & 23.2 & 1.2 & 24.5 & 20.1 & 0.8 & 20.9 \\
\hline
\end{tabular}

Gr. 1 = Grade 1 goitre, Gr. $2=$ Grade 2 goitre, TGR $=$ total goitre rate, $* \chi^{2}=67.3, P=0.0000$

When TGR observed in this study are compared with the 1986/7 study, there is a decline in the goitre prevalence rates in the Western, Southern and Sabaragamuwa Provinces with a marginal increase in the Central and Uva Provinces. In the Provinces of dry zone (North Central and North Western Province) an increase in the prevalence has been observed (Figure 1).

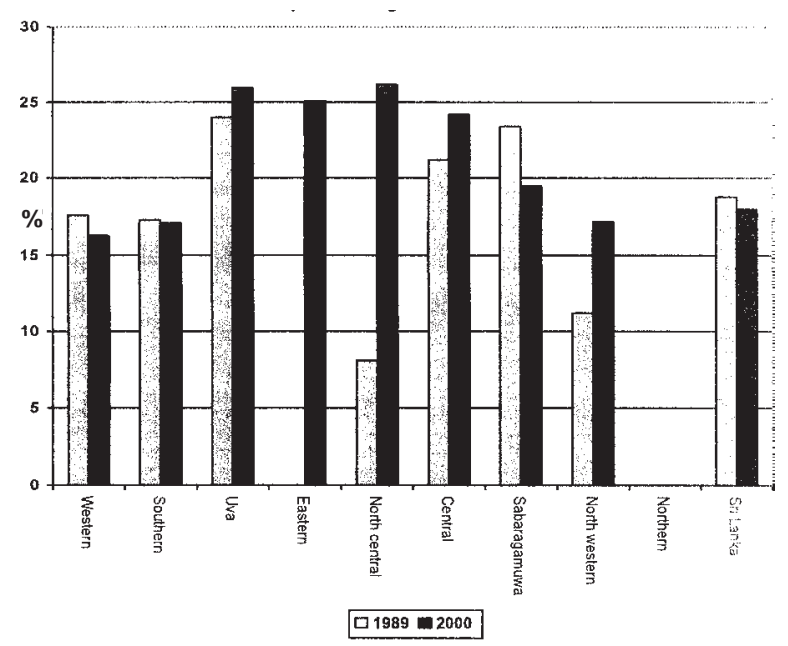

Figure 1. Comparison of goitre rates in 1988/89 and 2000/1.

The median UI concentrations were above $100 \mu \mathrm{g} / \mathrm{L}$ in all Provinces except Uva, indicating an adequate dietary intake of iodine (Table 2). The UI varied from $4.6 \mu \mathrm{g} / \mathrm{L}$ to $3206.4 \mu \mathrm{g} / \mathrm{L}$. The highest median urinary iodine level was reported in North Central Province $(231.3 \mu \mathrm{g} / \mathrm{L})$.

Table 2. Median urinary iodine excretion (UI) and salt iodine level of households in nine Provinces of Sri Lanka, 2000/1

\begin{tabular}{|c|c|c|c|c|c|}
\hline \multirow[b]{2}{*}{ Province } & \multirow[b]{2}{*}{$n$} & \multicolumn{2}{|c|}{$U I(\mu g / L)$} & \multicolumn{2}{|c|}{$\begin{array}{r}\text { Salt iodine adequacy } \\
\% \text { at }\end{array}$} \\
\hline & & Median* & Range & $n$ & $\begin{array}{l}\text { house- } \\
\text { hold** }\end{array}$ \\
\hline Western & 300 & 151.4 & $8.7-1148.5$ & 575 & 65.0 \\
\hline Southern & 300 & 122.4 & $10.6-0868.6$ & 624 & 59.1 \\
\hline Uva & 300 & 96.2 & $13.0-0641.6$ & 641 & 53.0 \\
\hline Eastern & 274 & 139.5 & $7.7-1124.6$ & 632 & 55.5 \\
\hline North Central & 300 & 231.3 & $14.8-1428.8$ & 660 & 37.4 \\
\hline Central & 300 & 122.5 & $8.9-1509.4$ & 662 & 37.0 \\
\hline Sabaragamuwa & 300 & 136.1 & $4.6-3206.4$ & 883 & 48.9 \\
\hline North Western & 300 & 180.7 & $6.7-1347.6$ & 692 & 38.0 \\
\hline Northern & 228 & 194.4 & $9.6-1748.0$ & 814 & 54.6 \\
\hline Sri Lanka & 2630 & 145.3 & 4.6ñ3206.4 & 6181 & 49.5 \\
\hline
\end{tabular}

Overall, $35.4 \%$ of the children had UI in the 'ideal' range $(100-199.9 \mu \mathrm{g} / \mathrm{L}) ; 30.6 \%$ with lower values $(<100 \mu \mathrm{g} / \mathrm{L})$ indicative of iodine deficiency and $16.3 \%$ with higher values (>300 mg/L), indicative of excessive iodine

Table 3. Frequency distribution of urine iodine levels of children 8-10 years by Provinces

\begin{tabular}{|c|c|c|c|c|c|c|c|}
\hline \multirow[t]{4}{*}{ Province } & \multirow[t]{4}{*}{ Total examined } & \multicolumn{6}{|c|}{ Percentage of urine iodine levels $(\mu \mathrm{g} / L)$} \\
\hline & & \multicolumn{3}{|c|}{ Deficiency } & \multicolumn{3}{|c|}{ No deficiency } \\
\hline & & $<20$ & $20-49.9$ & $50-99.9$ & $100-199.9$ & $200-299.9$ & $\geq 300$ \\
\hline & & Severe & Moderate & Mild & Ideal & $\begin{array}{l}\text { More than } \\
\text { adequate }\end{array}$ & $\begin{array}{l}\text { Excessive } \\
\text { iodine intake }\end{array}$ \\
\hline Western & 300 & 0.7 & 7.3 & 18.7 & 36.7 & 23.7 & 13. 0 \\
\hline Southern & 300 & 0.3 & 9.3 & 30.3 & 39.3 & 16.0 & 4. 7 \\
\hline Uva & 300 & 2.3 & 14.3 & 35.3 & 34.0 & 9.0 & 5. 0 \\
\hline Eastern & 280 & 4.6 & 6.4 & 23.2 & 32.9 & 13.2 & 19.6 \\
\hline North Central & 300 & 0.3 & 0.7 & 7.3 & 32.3 & 27.3 & 32.0 \\
\hline Central & 300 & 0.7 & 9.3 & 28.0 & 37.3 & 15.3 & 9. 3 \\
\hline Sabaragamuwa & 300 & 1.3 & 9.7 & 22.3 & 40.7 & 13.0 & 13.0 \\
\hline North Western & 300 & 1.7 & 2.7 & 18.3 & 31.3 & 20.0 & 26.0 \\
\hline Northern & 250 & 0.4 & 3.6 & 14.0 & 33.2 & 22.8 & 26.0 \\
\hline Sri Lanka & 2630 & 1.4 & 7.1 & 22.1 & 35.4 & 17.8 & 16. 3 \\
\hline
\end{tabular}


intake (Table 3 ). Only a small percentage (1.4\%) had very low values of $<20 \mu \mathrm{g} / \mathrm{L}$, indicative of severe deficiency of iodine intake, ranging from a value of $4.6 \%$ in the Eastern Province to a value of $0.3 \%$ in the Southern and North Central Provinces. The group that had UI of above $300 \mu \mathrm{g} / \mathrm{L}$ indicating a possible excessive iodine intake, the percentages ranged from $4.7 \%$ in the Southern Province to $32 \%$ in the North Central Province.

The majority of children (75\%) brought salt samples from their households. Almost all the salt samples had some iodine according to the results of rapid test kit. But the adequate iodination of salt was determined by changing into the dark purple colour in order to the test kit specification, i.e. at $25 \mathrm{ppm}$. According to the colour change, the adequate iodination of salt in households in the country was $49.5 \%$. The lowest level was observed in North Western Province, i.e. $37.4 \%$ and highest in Western Province, i.e. $65 \%$ (Table 2).

Table 4 shows the urinary iodine level at different cut-off points in relation to the total goitre rate and the adequacy of iodine level at households. When the UI levels were less than $20 \mu \mathrm{g} / \mathrm{L}$ the goitre rates were high $(39.1 \%)$, and when the UI levels were high ( $\geq 300 \mathrm{mg} / \mathrm{L})$ the goitre rates are also high $(20.4 \%)$. The adequacy of iodine level at households varied from high to low. This showed that the children with high UI levels had some other source to get iodine besides salt.

Table 4. Comparison of urinary iodine levels with the total goitre rate and the adequacy of salt iodine levels

\begin{tabular}{ccc}
\hline $\begin{array}{c}\text { Median urinary } \\
\text { iodine levels } \\
(\mu g / L)\end{array}$ & $\begin{array}{c}\text { Total goitre } \\
\text { rate* } \\
(\%)\end{array}$ & $\begin{array}{c}\text { Salt iodine } \\
\text { adequacy** } \\
(\%)\end{array}$ \\
\hline$<20$ & 39.1 & 68.0 \\
$20-49$ & 18.2 & 56.8 \\
$50-99$ & 18.5 & 61.2 \\
$100-199.9$ & 19.9 & 52.9 \\
$200-299.9$ & 17.2 & 45.7 \\
$\geq 300$ & 20.4 & 45.0 \\
Overall & $\mathbf{1 9 . 3}$ & $\mathbf{5 2 . 6}$ \\
\hline
\end{tabular}

$* \chi^{2}=9.0, \mathrm{P}=0.1 ; * * \chi^{2}=30.5, \mathrm{P}=0.0000$

\section{Discussion}

In this study, USI had normalised the UI to $145.3 \mathrm{mg} / \mathrm{L}$ in Sri Lanka. This effect indicator is highly sensitive to recent changes in iodine intake. In contrast, 5 years after USI, the GR was $20.9 \%$, indicating moderate to severe IDD by WHO/ICCIDD/UNICEF criteria [9]. Although thyroid size changes inversely in response to alterations in iodine intake, there is a lag before the GR normalises after iodine repletion. The duration of the lag period is unclear, with experts suggesting that it may last from months to years [10]. Cross-sectional studies also found a discrepancy between a normal UI and an elevated GR in the immediate post-USI period [11]. Present study has used the technique of palpation to measure the GR. In areas of mild-to-moderate IDD and for monitoring the effect of USI, measurement of thyroid size by ultrasonography is preferable to palpation [9]. Previous studies carried out in Sri Lanka before the USI was thyroid palpation to grade goitre. Hence palpation GR is suitable for comparative purposes before and after USI. In this study, intra-observer and inter-observer variations of thyroid palpation was minimised by using only five especially trained health personnel and reassessment of $50 \%$ of the sample by a medical officer trained for palpation, which gave $92 \%$ agreement.

According to the median UI levels, the present iodine status is satisfactory in seven out of nine provinces. The median UI levels in the Uva Province indicated 'mild iodine deficiency' while the levels in the North Central Province (NCP) indicated more than 'adequate' levels. In contrast, the total goitre rate in the NCP is among the highest in Sri Lanka. This Province has been considered as a non-endemic area in the past, indicating the need for further studies on the mechanism of goitre in the NCP. It stresses that multiple goitrogens were probably present. Deficiencies of selenium, iron and vitamin A were also common in this population and may have impaired the thyroid response to iodine repletion [12].

UI levels have not been assessed before the implementation of salt iodisation programme; hence it is not possible to assess the effectiveness of this programme based on the UI status. But another study in the year 2000 showed that median UI ranged from $105 \mu \mathrm{g} / \mathrm{L}$ to $152 \mu \mathrm{g} / \mathrm{L}$ among schoolgirls in low, intermediate and high goitre prevalent areas indicated in the 1986/7 study, with normal thyroid function tests except in four girls. In addition to that, the high prevalence of thyroglobulin antibodies $(\mathrm{TgAb})$ with an age-related increase have also been observed in that study [13].

In our study it was found that UI levels varied from $4.6 \mu \mathrm{g} / \mathrm{L}$ to $3206.4 \mu \mathrm{g} / \mathrm{L}$. Intake as high as $2000 \mu \mathrm{g} /$ day are unlikely to be obtained from normal diets [14]. The iodine concentration of up to $84 \mu \mathrm{g} / \mathrm{L}$ in drinking water was found in some part of the country, and this might contribute to the high level of urine iodine levels [15]. Therefore it is important to further investigate all these factors.

Of the 300 urine samples studied from the NCP, 59.3\% had values higher than the 'ideal' value, compared to $14 \%$ in the Uva Province, whereas both Provinces had similar total goitre rates $(26.2 \%$ and $26 \%)$. A recent study on selenium deficiency in south-west Sri Lanka showed that selenium deficiency in the soil was found in $24 \%, 24 \%$ and $48 \%$ of women living in the low, medium and high goitre prevalent villages respectively[15].

However, the iodine status of seven provinces was satisfactory in spite of the fact that the proportion of households with intake of salt with adequate levels of iodine was lower than $90 \%$ as indicated by the WHO/ ICCIDD/UNICEF. It is interesting to note also that low and high urinary iodine levels are associated with the high GR and low salt iodine levels. Additional studies are needed to explore these observations. 


\section{Conclusions}

Sri Lanka has achieved satisfactory iodine status as indicated by UI levels. It is important to develop a surveillance system to monitor UI levels and other indicators as necessary, so that it will be possible to take timely decisions regarding future changes in the iodisation programme. Consideration must be given to review the specifications for iodine content of iodised salt as recommended by ICCIDD/UNICEF/WHO in 1995, and making appropriate modifications in the legal enactment [9]. The high UI levels noted in the NCP along with a high total goitre rate indicates the need for further study involving environmental studies.

\section{Acknowledgements}

We thank UNICEF for providing the funds for the study and assistance to establish the laboratory facilities. We appreciate the services provided by Professor MM Mohidduzzaman, Assistant Professor of Biochemistry, Dhaka University, Bangladesh, to establish the urine iodine laboratory and train the laboratory staff. We thank Dr. CS Pandav (Regional ICCIDD coordinator for south-east Asia), and Dr. Karmakar of ICCIDD, New Delhi, for their help in the establishment of the iodine laboratory. We are grateful to the Provincial Directors of Education, the Principals of schools, teachers, parents, and children who participated.

\section{References}

1. World Health Organisation. Nutrition in Southeast Asia. Regional Office for Southeast Asia. New Delhi, 2000.

2. Mahadeva K, Seneviratne DA, Jayatilleke DB, Shanmuganathan SS, Premachandra P, et al. Further studies on the problem of goitre in Ceylon. British Journal of Nutrition 1968; 22: 527-34.

3. Stanbury JB, Hetzel BS. Endemic Goitre and Endemic Cretinism: Iodine Nutrition in Health and Disease. New York: John Wiley and Sons, 1980.

4. Wilson DC. Goitre in Ceylon and Nigeria. British Journal of Nutrition 1954; 8: 90-9.
5. Deo MG, Subramanian TAV. Iodine metabolism in children and women with goitre in Ceylon. British Journal of Nutrition 1971; 25: 97-105.

6. Fernando MA, Balasuriya S, Herath KB, Katugampola S. Endemic goitre in Sri Lanka. Asia-Pacific Journal of Public Health 1989; 3: 11-9.

7. World Health Organisation (WHO). Indicators for assessing iodine deficiency disorders and their control through salt iodisation, WHO/NUT/94.6, WHO, UNICEF, ICCIDD, Geneva, 1994:1-55.

8. Ohashi T, Yamaki M, Pandav CS, Karmarkar MG, Irie M. Simple microplate method for determination of urinary iodine. Clinical Chemistry 2000; 46: 529-36.

9. World Health Organisation. Progress towards the elimination of iodine deficiency disorders (IDD). WHO/ NHD/99.4, 1999.

10. Delange F, De Benoist B, Pretell E, Dunn JT. Iodine deficiency in the world: where do we stand at the turn of the century? Thyroid 2001; 11: 437-47.

11. Jooste PL, Weight MJ, Lombard CJ. Short-term effectiveness of mandatory iodization of table salt, at an elevated iodine concentration on the iodine and goiter status of schoolchildren with endemic goiter. American Journal of Clinical Nutrition 2000; 71: 75-80.

12. Zimmermann M, Adou P, Torresani T, Zeder C, Hurrell RF. Persistence of goiter despite oral iodine supplementation in goitrous children with iron deficiency anaemia in Côte d'Ivoire. American Journal of Clinical Nutrition; 2000;71: 88-93.

13. Premawardhana LDKE, Parkes AB, Smyth PPA, Wijeyaratne $\mathrm{CN}$, Jayasinghe A, et. al. Increased prevalence of thyroglobulin antibodies in Sri Lanka schoolgirls - is iodine the cause? European Journal of Endocrinology 2000; 143: $185-8$.

14. Thomson CD. Dietary recommendation for iodine around the World. IDD Newsletter, ICCIDD 2002; 18: 38-41.

15. Fordyse CD, Johnson CC, Navaratna UR, Appleton JD, Dissanayaka CB. Selenium and iodine in soil, rice and drinking water in relation to endemic goitre in Sri Lanka. Science Total Environment 2000; 263:127-41. 